\title{
FOOD CHOICES, PHYSICAL ACTIVITY AND METABOLIC HEALTH IN OBESE PATIENTS
}

\author{
Hanna Alajõe ${ }^{1}$, Kadri Suija ${ }^{1}$, Anneli Rätsep ${ }^{1}$, Ruth Kalda ${ }^{1}$, \\ MARGUS LEMBER ${ }^{2}$ \\ ${ }^{1}$ Institute of Family Medicine and Public Health, Faculty of Medicine, \\ University of Tartu \\ ${ }^{2}$ Department of Internal Medicine, Institute of Clinical Medicine, Faculty of Medicine, \\ University of Tartu and Tartu University Hospital
}

\begin{abstract}
The aim of the current study was to analyse the food choices and physical activity of obese adult Estonian persons, and associations with the prevalence of metabolic syndrome. The study was carried out on 76 patients aged over 35 years whose body mass index was $\geq 30 \mathrm{~kg} / \mathrm{m}^{2}$. The subjects were recruited through family physicians. The subjects' consumption of three food groups (fruit, vegetables, whole-grain products) and physical activity based on the IPAQ questionnaire was compared with the prevalence of metabolic syndrome based on five indicators (waist circumference, triglycerides, HDL-cholesterol and fasting plasma glucose, blood pressure). The prevalence of metabolic syndrome was found to be $50 \%$. The results of the study did not show statistically significant correlations between prevalence of metabolic syndrome and age or gender. Neither were there any significant age or gender differences in the subjects' nutritional and activity behaviour. Comparison of the nutritional behaviour of persons with and without the metabolic syndrome showed that daily consumers of fruit had a 4.48 times lower risk of metabolic syndrome than those who ate fruit more seldom. No statistically significant correlation was found between physical activity and prevalence of metabolic syndrome. Based on the current study, the daily consumption of fruit can be an essential protective factor against metabolic syndrome in obese patients and provides a simple recommendation physicians can give their patients to follow.
\end{abstract}

Keywords: obesity; physical activity; eating habits; metabolic syndrome 


\section{INTRODUCTION}

According to the World Health Organisation (WHO) criteria, obesity is defined by having a body mass index (BMI) of more than $30 \mathrm{~kg} / \mathrm{m} 2$ [41]. In 2014, 13\% of the world population [40] and 32\% or approximately one third of the population of Estonia [12] were obese.

The metabolic syndrome (MetS) is a complex of risk factors for diabetes and cardiovascular disease (CVD) [2]. An estimated $20-25 \%$ of the world's adult population suffer from MetS [3] and only $6-32 \%$ of obese persons do not have MetS, meaning they are metabolically healthy [27].

Obese persons have a 1.7-1.9 times higher risk of CVD, and this is directly correlated with the person's BMI; for example in the case of morbid obesity $\left(B M I \geq 40 \mathrm{~kg} / \mathrm{m}^{2}\right)$, the risk of CVD can already be 3.1 times higher [19]. Patients with MetS, however, have a 2.3 times higher cardiovascular morbidity and 2.4 times higher CVD mortality, 2 times higher risk of myocardial infarction, 2.3 times higher risk of stroke and 1.6 times higher over-all mortality [22]. In addition, according to different estimations, they have a 2-11 times higher risk of type 2 diabetes [32].

The exact reason why some obese people are healthier than others is not known [14]. The possible causes are several factors of lifestyle and heredity, like physical activity, genetic background, nutrition, etc. [1].

For example, a meta-analysis summarising the correlations between fruit and vegetable consumption and MetS found that consumption of fruit and vegetables has a positive influence on the decrease of diastolic blood pressure but not on the general prevalence of MetS [33]. Gender has also been found to be a protective factor of metabolic health; namely, several studies have found that in obese women MetS occurs more seldom than in men $[11,21,30]$.

It has also been found that the probability of "metabolic health" decreases with age $[6,11,23,29,34,39]$. Therefore, the absence of MetS in obese persons has been considered only a transitional phase before its onset [23]. At that, in the case of the elderly, the problem can lie in the inappropriateness of the BMI as an indicator of their health and obesity, as it does not show the amount of the adipose tissue, and thus, research results can mistakenly show a decrease in the proportion of metabolically healthy obesity with an increase of age [1].

There have also been many studies of associations between physical activity and metabolic health. For example comparisons of the level of physical activity in patients with MetS and without MetS $[9,18,24]$, leisure time physical activity in relation to MetS $[15,35]$, sedentary time in relation to MetS [24, 31] and intervention studies of physical activity for obese persons with MetS [7, 
20,25]. Still, no consensus has been reached as a result of these studies on the association between the prevalence of MetS and physical activity.

As obesity is very prevalent, and having MetS increases the risk of morbidity even more, it is essential to find the reasons why some obese people are healthier than others and give obese persons simple recommendations for staying healthy.

The aim of the current study was to analyse food choices and physical activity of obese adult Estonian persons, associated factors and correlations with MetS.

\section{MATERIAL AND METHODS}

The study is based on the cross-sectional research project "Associations between chronic diseases and ageing, changes in bone, fat and muscle tissue and impact of endocrine factors". The study was supported by the Estonian Research Agency's grant Institutional Research Funding 2-8.

The subjects were adult persons with a BMI over $30 \mathrm{~kg} / \mathrm{m} 2$ who volunteered to participate in the study. Persons aged over 35 years were recruited so that the potential health changes associated with obesity would have been developed. The subjects were invited to participate in the study through family physicians of Tartu and Tartu County ( 24 in total). The subjects were recruited into the study from 1 May 2016 to 28 June 2018.

Family physicians measured the patients' blood pressure, body weight and height, took blood samples and gave them questionnaires to be filled in at home. The blood samples were analysed at Tartu laboratory of Synlab.

The current study is based on three parts of the questionnaire: general information, questionnaire on lifestyle and International Physical Activity Questionnaire (IPAQ). The patients were invited to a densitometric investigation where the questionnaires filled by them were collected.

The following five indicators were used as MetS criteria: glucose, HDLcholesterol and triglycerides levels in blood, blood pressure values and waist circumference. For diagnosing of MetS, at least three indicators out of five had to exceed the set level:

1. Waist circumference greater or equal to $102 \mathrm{~cm}$ in men and $88 \mathrm{~cm}$ in women.

2. Triglycerides level in blood higher or equal to $1.7 \mathrm{mmol} / \mathrm{l}$. 
3. HDL-cholesterol level in blood less than $1.0 \mathrm{mmol} / \mathrm{l}$ in men and $1.3 \mathrm{mmol} / \mathrm{l}$ in women.

4. Systolic blood pressure higher or equal to $130 \mathrm{mmHg}$.

5. Glucose level in blood higher or equal to $5.6 \mathrm{mmol} / \mathrm{l}$. [2]

The patients were considered metabolically "healthy" if they had no MetS indicators or had less than three indicators out of five exceeding the criteria.

Associations of the prevalence of MetS and the subjects' food choices and physical activity were analysed using questionnaires filled by the subjects themselves. The questionnaire included three binary questions on nutrition: "How often do you eat fruit?", "How often do you eat vegetables?" and "How often do you eat whole-grain products?", to which the subjects replied if it was daily or less than daily.

The subject was considered a healthy eater if she/he consumed products of at least two food groups (fruit, vegetables, whole-grain products) daily.

To measure physical activity, the short form of IPAQ was used, which is suitable for retrospective studies [8]. The questionnaire consists of seven questions about physical activities of different intensity and their duration during the last week. Activities of different intensity were weighed according to categories, and MET-minutes (metabolic equivalent) per week were found. The MET-minute shows estimated resting energy expenditure. Based in this, the respondents were divided into three groups: persons with high, moderate and low physical activity.

Statistical analysis was performed with Stata/IC 14.2 data analysis program. To find correlations between categorical variables, the Fisher test was used and, when statistically significant correlations were found, the logistic regression model was used to find the direction of the correlation.

The study has a permission from the Research Ethics Committee of the University of Tartu 255/M-13.

\section{RESULTS}

Altogether 88 patients were recruited; 12 of them were left out as one or more significant variables for performing the analysis were missing; thus, the final sample included 76 persons. The subjects' mean age was 51 years; the youngest of them was 34 and the oldest 75 years old. The demographic data of the study group are presented in Table 1 . 
Table 1. Description of the sample

\begin{tabular}{l|ccc|ccc|ccc}
\hline & \multicolumn{3}{|c|}{ Men } & \multicolumn{3}{c|}{ Women } & \multicolumn{3}{c}{ Total } \\
\cline { 2 - 11 } & N & $\%$ & SD & N & $\%$ & SD & N & $\%$ & SD \\
\hline Sample & 28 & 37 & & 48 & 63 & & 76 & 100 \\
\hline Mean age & 51 & & 10 & 51 & & 10 & 51 & 10 \\
\hline Mean BMI & 31 & & 9 & 36 & & 7 & 35 & 8 \\
\hline Prevalence of MetS & 17 & 45 & & 21 & 55 & & 38 & 50 & \\
\hline
\end{tabular}

During the study, the BMI was calculated twice - first by the family physician to confirm the patient's suitability for the study and, for the second time, during data analysis based on the results of the densitometric study. Therefore, the body weight received as a result of the densitometric study is used below, as it was standardised for all subjects. The subjects' lowest BMI was $29.34 \mathrm{~kg} /$ $\mathrm{m}^{2}$, which is not considered obesity, although it is on the borderline between overweight and obesity. The highest BMI was $51.75 \mathrm{~kg} / \mathrm{m}^{2}$.

Consumption of food groups by the sample is shown in Figure 1. There were only 8 persons who consumed the food of all the three groups (fruit, vegetables, whole-grain products) daily. When the subjects were divided into two groups according to a more lenient criterion (eating two out of the three food groups daily), they were divided nearly equally; the group of healthy eaters included 37 people and the group of less healthy eaters 39.

According to physical activity, the subjects were divided into three groups: low, moderate and high physical activity. The distribution of the sample into physical activity groups is shown in Figure 2. In the case of four patients, this could not be calculated, as they had answered "do not know". On average, sedentary time spent by subjects was 385 minutes per day $(s=198)$.

Table 2. Levels of metabolic syndrome indicators in subjects

\begin{tabular}{lcc}
\hline & Mean & $95 \% \mathrm{Cl}$ \\
\hline Triglycerides $(\mathrm{mmol} / \mathrm{l})$ & 1.87 & $1.6-2.2$ \\
\hline HDL-cholesterol $(\mathrm{mmol} / \mathrm{l})$ & 1.35 & $1.28-1.43$ \\
\hline Systolic blood pressure $(\mathrm{mm} \mathrm{Hg})$ & 132 & $129-135$ \\
\hline Glucose $(\mathrm{mmol} / \mathrm{l})$ & 5.68 & $5.47-5.88$ \\
\hline Waist circumference $(\mathrm{cm})$ & 111 & $109-114$ \\
\hline
\end{tabular}




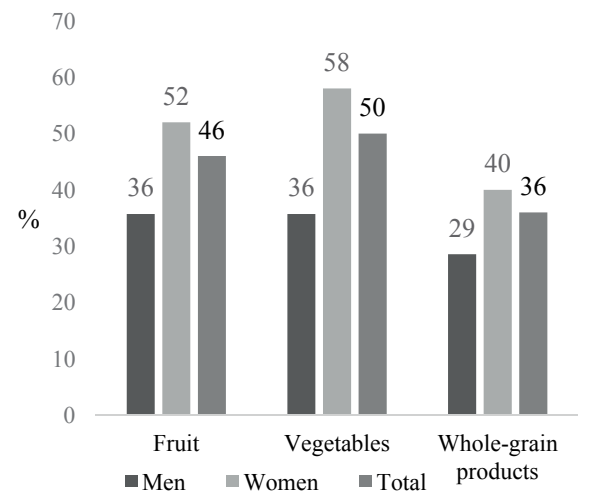

Figure 1. Percentage of daily food groups consumption in Estonian obese patients, by gender and in total

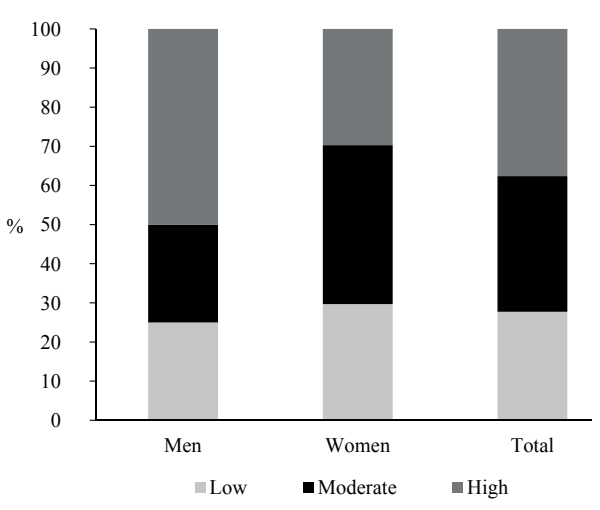

Figure 2. Physical activity in Estonian obese patients based on IPAQ, by gender and in total

MetS criteria were fulfilled by exactly half of the subjects; consequently, its prevalence was $50 \%$. In addition, the prevalence of each MetS indicator was viewed separately. Triglycerides level was heightened in $41 \%$, systolic blood pressure in $48 \%$, glucose in $49 \%$, waist circumference in $100 \%$ of subjects; HDL-cholesterol level was lower in $19 \%$ of them.

Based on the nutrition groups, no statistically significant correlation was found between the prevalence of MetS and nutrition ( $\mathrm{F}=0.17)$. To find the correlations between the prevalence of MetS and consumption of specific food groups, logistic regression analysis was performed, which showed a significant correlation between the consumption of fruit and the prevalence of MetS (Table 3). When fruit was consumed less often than daily, the risk of MetS was 4.48 times higher than at daily consumption $(\mathrm{p}=0.004)$. Although the result was statistically significant, its confidence interval was very broad. No statistically significant correlation was found between the consumption of vegetables and whole-grain products and the prevalence of MetS $(\mathrm{p}=0.62$ and $\mathrm{p}=0.63$ respectively).

Table 3. Logistic regression model of food choices and prevalence of the metabolic syndrome

\begin{tabular}{lccc}
\hline Metabolic syndrome & Odds ratio & p-value & 95\% confidence interval \\
\hline Fruit & 4.48 & 0.004 & $1.60-12.55$ \\
\hline Vegetables & 0.78 & 0.62 & $0.30-2.08$ \\
\hline Whole-grain products & 0.77 & 0.63 & $0.27-2.22$ \\
\hline
\end{tabular}


No statistically significant correlation was found between physical activity and the prevalence of MetS. Neither was a statistically significant correlation found between the prevalence of MetS and sedentary time $(\mathrm{p}=0.5)$.

\section{DISCUSSION}

The current study analysed the nutrition and physical activity of 76 obese patients aged 34-75 years in primary care. The subjects' mean BMI was $35 \mathrm{~kg} /$ $\mathrm{m}^{2}$, and half of them had MetS.

It could be surprising that only half of the obese subjects met the MetS criteria. Previously, it has been estimated that only $6-32 \%$ of obese persons are "metabolically healthy" [27]. A study conducted in Finland found that only $3.3 \%$ of obese persons could not be diagnosed with MetS [26]. A study conducted in Estonia estimated that the prevalence of MetS was $26 \%$ of the general population [12].

The relatively low prevalence of MetS among the obese persons in the current study could be explained by notably higher physical activity than in other studies $[9,18,26]$. In the current study, $38 \%$ of the subjects were highly, $35 \%$ moderately and $28 \%$ lowly physically active. This distribution is rather unusual compared to earlier studies. Earlier, it has been found that up to $80 \%$ of the obese have a low physical activity level [9]. A reason for the current results can be that $54 \%$ of the subjects reside in rural areas, while according to the last Estonian census only $37 \%$ of people live outside of towns [10]. People living in rural areas may do more gardening and other housework that increase their physical activity. IPAQ, which was used in the current study, differs from several other physical activity questionnaires namely because it takes into consideration not only leisure time physical activity but also physical activity resulting from daily chores and physical work. This is supported by a study conducted in Estonia, which was also based on IPAQ and found a statistically significant positive correlation between people's place of residence and physical activity [28].

It was also found that the subjects' mean sedentary time was 385 minutes per day. The result was not statistically significantly related to the prevalence of MetS but shows again that the sample of the current study was more active than obese persons on average, as it is similar to the sedentary time of general population in earlier studies [4] Previously, it has been found that obese persons spend more time sedentarily than the average person [16]. 
As a result of the study, it was found that fruit was consumed daily by $46 \%$, vegetables by $50 \%$ and whole-grain products by $36 \%$ of the subjects. The Estonian National Dietary Survey found that, on average, Estonians ate 2 portions of fruit and vegetables daily, and there was no difference between normalweight and obese persons [37]. Estonians consume whole-grain products in the form of porridges and bread products 16 portions per week, obese persons 17 portions per week [36]. Thus, the findings of the current study were surprising - the subjects' nutrition was considerably less healthy than of Estonians in general, even of other obese people. The difference in consumption of wholegrain products compared to The National Dietary Survey could result from the wording of the question. In The National Dietary Survey, the questions included more concrete food items like whole-grain bread, brown bread, porridges, etc., while in the current study, the term "whole-grain products" was used, which the subjects need not have always understood.

The current study found a statistically significant correlation between daily consumption of fruit and MetS prevalence, while at daily consumption of fruit, the risk of MetS was 4.48 times lower. A similar result was also received in meta-analysis which studied the influence of fruit and vegetable on MetS and its individual indicators. This analysis, however, revealed only a correlation between fruit and vegetable consumption and blood pressure, not with the prevalence of MetS in general [33].

The current study did not find statistically significant correlations between the prevalence of MetS or its individual indicators and consumption of vegetables and whole-grain products. It is possible that, to find a connection between nutrition as a whole and MetS, nutrition should be examined in greater detail, like it has been done in several earlier studies which have found a statistically significant correlation $[5,13,17,38]$.

A weakness of the study is using self-reported physical activity and food choices for analysis. The conductors of the study could not check whether the results could be influenced by social desirability or an information bias. Still, studies carried out with similar methodology were used at the comparison of results. The current study can include a selection bias. As the sample was small, it is possible that the people participating in the study were more interested in participation than average representatives of the obese population. Due to the research design, causal conclusions can't be made. On the other hand, researching the lifestyle and health of obese people could help prevent disease. Early interventions are necessary to help alleviate the seriousness of obesity-related illnesses. 


\section{CONCLUSIONS}

The current study did not find any correlations between physical activity, age, gender and the prevalence of MetS in obese patients. The prevalence of metabolic syndrome was $50 \%$. The dietary choices of the participants were not in accordance with dietary guidelines. Physical activity, on the other hand, was higher than expected of an obese group. Based on nutritional behaviour, a significant correlation was found that daily consumption of fruit decreases the risk of having MetS 4.48 times. Based on this, obese patients can be recommended to consume fruit as it is an essential factor in prevention of more severe diseases associated with obesity.

\section{REFERENCES}

1. Alam I., Ng T.P., Larbi A. (2012). Does Inflammation Determine Whether Obesity Is Metabolically Healthy or Unhealthy? The Aging Perspective. Mediators of Inflammation, 2012, Article ID 456456. https://doi.org/10.1155/2012/456456

2. Alberti K.G.M.M., Eckel R.H., Grundy S.M., et al. (2009). Harmonizing the Metabolic Syndrome: A Joint Interim Statement of the International Diabetes Federation Task Force on Epidemiology and Prevention; National Heart, Lung, and Blood Institute; American Heart Association; World Heart Federation; International Atherosclerosis Society; and International Association for the Study of Obesity. Circulation, 120, 16, 1640-1645. https://doi.org/10.1161/CIRCULATIONAHA.109.192644

3. Alberti K.G.M.M., Zimmet P., Shaw J. (2006). Metabolic syndrome - a new world-wide definition. A Consensus Statement from the International Diabetes Federation. Diabet Med, 23, 5, 469-480. https://doi.org/10.1111/j.1464-5491.2006.01858.x

4. Bullock V.E., Griffiths P., Sherar L.B., et al. (2017). Sitting time and obesity in a sample of adults from Europe and the USA. Ann Hum Biol, 44, 3, 230-236. https://doi.org/10.1080/03014460.2016.1232749

5. Camhi S.M., Whitney Evans E., Hayman L.L., et al. (2015). Healthy eating index and metabolically healthy obesity in U.S. adolescents and adults. Prev Med (Baltim), 77, 23-27. https://doi.org/10.1016/j.ypmed.2015.04.023

6. Chiheb S., Cosson E., Banu I., et al. (2016). Are Obese Individuals with no Feature of Metabolic Syndrome but Increased Waist Circumference Really Healthy? A Cross Sectional Study. Exp Clin Endocrinol Diabetes, 124, 07, 410-416. https://doi.org/10.1055/s-0035-1569264

7. Chu P., Gotink R.A., Yeh G.Y., et al. (2016). The effectiveness of yoga in modifying risk factors for cardiovascular disease and metabolic syndrome: A 
systematic review and meta-analysis of randomized controlled trials. Eur J Prev Cardiol, 23, 3, 291-307. https://doi.org/10.1177/2047487314562741

8. Craig C.L., Marshall A.L., Sjöström M., et al. (2003) International Physical Activity Questionnaire: 12-Country Reliability and Validity. Med Sci Sport Exerc, 35, 8, 1381-1395. https://doi.org/10.1249/01.MSS.0000078924.61453.FB

9. Donini L.M., Merola G., Poggiogalle E., et al. (2016). Disability, Physical Inactivity, and Impaired Health-Related Quality of Life Are Not Different in Metabolically Healthy vs. Unhealthy Obese Subjects. Nutrients, 8, 12, 759. https://doi.org/10.3390/nu8120759

10. Eesti Statistikaamet (2011). Rahva- ja eluruumide loendus. RL006: Rahvaarv, pindala ja asustustihedus haldusüksuse järgi. Available at: http://andmebaas. stat.ee/Index.aspx?lang=et\&DataSetCode=RL006. (Accessed January 21, 2019)

11. Eftekharzadeh A., Asghari G., Serahati S., et al. (2017). Predictors of incident obesity phenotype in nonobese healthy adults. Eur J Clin Invest, 47, 5, 357-365. https://doi.org/10.1111/eci.12743

12. Eglit T., Ringmets I., Lember M., et al. (2013). Obesity, High-Molecular-Weight (HMW) Adiponectin, and Metabolic Risk Factors: Prevalence and GenderSpecific Associations in Estonia. PLoS One, 8, 9, e73273.

https://doi.org/10.1371/journal.pone.0073273

13. Garcia M., Bihuniak J., Shook J., et al. (2016). The Effect of the Traditional Mediterranean-Style Diet on Metabolic Risk Factors: A Meta-Analysis. Nutrients, 8, 3, 168. https://doi.org/10.3390/nu8030168

14. Gonçalves C.G., Glade M.J., Meguid M.M. (2016). Metabolically healthy obese individuals: Key protective factors. Nutrition, 32, 1, 14-20. https://doi.org/10.1016/j.nut.2015.07.010

15. He D., Xi B., Xue J., et al. (2014). Association between leisure time physical activity and metabolic syndrome: a meta-analysis of prospective cohort studies. Endocrine, 46, 2, 231-240. https://doi.org/10.1007/s12020-013-0110-0

16. Heinonen I., Helajärvi H., Pahkala K., et al. (2013). Sedentary behaviours and obesity in adults: the Cardiovascular Risk in Young Finns Study. BMJ Open, 3, 6, e002901. https://doi.org/10.1136/bmjopen-2013-002901

17. Jessri M., Wolfinger R.D., Lou W.Y., et al. (2017). Identification of dietary patterns associated with obesity in a nationally representative survey of Canadian adults: application of a priori, hybrid, and simplified dietary pattern techniques. Am J Clin Nutr, 105, 3, 669-684. https://doi.org/10.3945/ajcn.116.134684

18. Kazaz İ., Angin E., Kabaran S., et al. (2018). Evaluation of the physical activity level, nutrition quality, and depression in patients with metabolic syndrome. Medicine (Baltimore) 97, 18, e0485. https://doi.org/10.1097/MD.0000000000010485 
19. Khan S.S., Ning H., Wilkins J.T., et al. (2018). Association of Body Mass Index With Lifetime Risk of Cardiovascular Disease and Compression of Morbidity. JAMA Cardiol, 3, 4, 280. https://doi.org/10.1001/jamacardio.2018.0022

20. Lin X., Zhang X., Guo J., et al. (2015). Effects of Exercise Training on Cardiorespiratory Fitness and Biomarkers of Cardiometabolic Health: A Systematic Review and Meta-Analysis of Randomized Controlled Trials. J Am Heart Assoc, 4, 7. https://doi.org/10.1161/JAHA.115.002014

21. Matta J., Nasreddine L., Jomaa L., et al. (2016). Metabolically Healthy Overweight and Obesity Is Associated with Higher Adherence to a Traditional Dietary Pattern: A Cross-Sectional Study among Adults in Lebanon. Nutrients, 8, 7, 432. https://doi.org/10.3390/nu8070432

22. Mottillo S., Filion K.B., Genest J., et al. (2010). The Metabolic Syndrome and Cardiovascular Risk. J Am Coll Cardiol, 56, 14, 1113-1132. https://doi.org/10.1016/j.jacc.2010.05.034

23. Navarro-González D., Sánchez-Íñigo L., Fernández-Montero A., et al. (2016). Are all metabolically healthy individuals with obesity at the same risk of diabetes onset? Obesity, 24, 12, 2615-2623. https://doi.org/10.1002/oby.21667

24. Oliveira R.G. de, Guedes D.P. (2016). Physical Activity, Sedentary Behavior, Cardiorespiratory Fitness and Metabolic Syndrome in Adolescents: Systematic Review and Meta-Analysis of Observational Evidence. PLoS One, 11, 12, e0168503. https://doi.org/10.1371/journal.pone.0168503

25. Ostman C., Smart N.A., Morcos D., et al. (2017). The effect of exercise training on clinical outcomes in patients with the metabolic syndrome: a systematic review and meta-analysis. Cardiovasc Diabetol, 16, 1, 110. https://doi.org/10.1186/s12933-017-0590-y

26. Pajunen P., Kotronen A., Korpi-Hyövälti E., et al. (2011). Metabolically healthy and unhealthy obesity phenotypes in the general population: the FIN-D2D Survey. BMC Public Health, 11, 1, 754. https://doi.org/10.1186/1471-2458-11-754

27. Pataky Z., Bobbioni-Harsch E, Golay A. (2010). Open questions about metabolically normal obesity. Int J Obes, 34, S2, S18-S23. https://doi.org/10.1038/ijo.2010.235.

28. Pechter Ü., Suija K., Kordemets T., et al. (2012). Physical activity and exercise counselling: a cross-sectional study of family practice patients in Estonia. Qual Prim Care, 20, 5, 355-63.

29. Pramyothin P., Limpattanachart V., Dawilai S., et al. (2017). Fat-Free Mass, Metabolically Healthy Obesity, and Type 2 Diabetes in Severely Obese Asian Adults. Endocr Pract, 23, 8, 915-922. https://doi.org/10.4158/EP171792.OR

30. Qiao Q., DECODE Study Group (2006). Comparison of different definitions of the metabolic syndrome in relation to cardiovascular mortality in European men and women. Diabetologia, 49, 12, 2837-2846.

https://doi.org/10.1007/s00125-006-0438-6 
31. Rezende L.F.M. de, Rey-López J.P., Matsudo V.K.R., et al. (2014). Sedentary behavior and health outcomes among older adults: a systematic review. BMC Public Health, 14, 1, 333. https://doi.org/10.1186/1471-2458-14-333

32. Shin J.-A., Lee J.-H., Lim S.-Y., et al. (2013). Metabolic syndrome as a predictor of type 2 diabetes, and its clinical interpretations and usefulness. J Diabetes Investig, 4, 4, 334-43. https://doi.org/10.1111/jdi.12075

33. Shin J.Y., Kim J.Y., Kang H.T., et al. (2015). Effect of fruits and vegetables on metabolic syndrome: a systematic review and meta-analysis of randomized controlled trials. Int J Food Sci Nutr, 66, 4, 416-425. https://doi.org/10.3109/09637486.2015.1025716

34. Zamrazilova H., Weiss R., Hainer V., et al. (2016). Cardiometabolic Health in Obese Adolescents Is Related to Length of Obesity Exposure: A Pilot Study. J Clin Endocrinol Metab, 101, 8, 3088-3095. https://doi.org/10.1210/jc.2016-1706

35. Zhang D., Liu X., Liu Y., et al. (2017). Leisure-time physical activity and incident metabolic syndrome: a systematic review and dose-response meta-analysis of cohort studies. Metabolism, 75, 36-44. https://doi.org/10.1016/j.metabol.2017.08.001

36. Tervise Arengu Instituut (2014). Rahvastiku toitumise uuring. RTU027: Keskmine toitude tarbimine nädalas soo, vanuse ja kehamassiindeksi (KMI) järgi.

37. Tervise Arengu Instituut (2016). Rahvastiku toitumise uuring. RTU047: Enesehinnanguline tarbitud puu- ja köögiviljaportsjonite arv päevas soo, vanuse ja kehamassiindeksi (KMI) järgi.

38. Turner-McGrievy G., Harris M. (2014). Key Elements of Plant-Based Diets Associated with Reduced Risk of Metabolic Syndrome. Curr Diab Rep, 14, 9, 524. https://doi.org/10.1007/s11892-014-0524-y

39. Velho S., Paccaud F., Waeber G., et al. (2010). Metabolically healthy obesity: different prevalences using different criteria. Eur J Clin Nutr, 64, 10, 1043-1051. https://doi.org/10.1038/ejcn.2010.114.

40. WHO | Obesity and overweight (2017). WHO.

41. World Health Organization (1995). Physical status: the use and interpretation of anthropometry. Report of a WHO Expert Committee. World Health Organ Tech Rep Ser 854, 1-452.

\section{Address for correspondence:}

Hanna Alajõe

L. Puusepa 1a 50406 Tartu, Estonia

E-mail: hanna.alajoe@gmail.com

Phone: +3727319211 